\title{
The laryngeal mask airway in obstetrical anaesthesia
}

\author{
P.S. Gataure FRCA, ${ }^{*}$ J.A. Hughes FRCA $\dagger$
}

\begin{abstract}
The laryngeal mask airway (LMA) has been used extensively to provide a safe airway in spontaneously breathing patients who are not at risk from aspiration of gastric contents. The role of the LMA in the event of a failed intubation in an obstetrical patient, and its place in a failed intubation drill remains unclear. Two hundred and fifty consultant obstetric anaesthetists in the United Kingdom were asked to complete an anonymous questionnaire regarding their views about using the laryngeal mask airway (LMA) in obstetrical anaesthesia. The LMA was available in $91.4 \%$ of obstetric units. Seventy-two per cent of anaesthetists were in favour of using the LMA to maintain oxygenation when tracheal intubation had failed and ventilation using a face mask was inadequate. Twenty-four respondents had had personal experience with the LMA in obstetrical anaesthesia, eight of whom stated that the LMA had proved to be a lifesaver. We believe that the LMA has a role in obstetrical anaesthesia when tracheal intubation has failed and ventilation using a face mask proves to be impossible, and it should be inserted before attempting cricothyroidectomy.
\end{abstract}

Le masque laryngé (ML) est couramment utilisé pour maintenir la perméabilité des voies aériennes en respiration spontanée chez le patient qui ne court pas de risque d'aspiration du contenu gastrique. Le rôle du ML pour l'intubation trachéale impossible en obstétrique et sa situation sur l'organigramme de l'intubation impossible n'ont pas été précisés. Au RoyaumeUni, on a demandé à 250 anesthésistes de compléter un questionnaire anonyme sollicitant leur opinion sur l'usage du ML en anesthésie obstétricale. Le masque laryngé est dis-

\section{Key words}

ANAESTHESIA: obstetrical;

EQUIPMENT: laryngeal mask airway;

COMPLICATIONS: intubation, failed; aspiration, pulmonary.

From the Department of Anaesthesia, ${ }^{*}$ the Princess of Wales Hospital, Coity road, Bridgend, Mid-Glam, CF31 1RQ, and the Department of Anaesthesia, $\uparrow$ Morriston Hospital,

Morriston, Swansea, SA6 6NL.

Address correspondence to: Dr. P.S. Gataure, The Department of Anaesthesia, The Princess of Wales Hospital, Coity road, Bridgend, Mid-Glam. CF31 IRQ.

Accepted for publication 8th October, 1994. ponible dans $91,4 \%$ des services d'obstétrique. Soixante-douze pour cent des répondants se sont dits d'accord pour utiliser le $M L$ pour le maintien de l'oxygénation lorsque l'intubation est impossible et la ventilation impraticable avec un masque facial. Vingt-quatre répondants ont rapporté une expérience personnelle avec le $M L$ en anesthésie obstétricale dont huit ont été salvatrices. Nous croyons que le ML a un rôle en anesthésie obstétricale lorsque l'intubation trachéale est impossible et lorsqu'on est incapable de ventiler au masque facial, et qu'on devrait linsérer avant de tenter la cricothyrotomie.

The consequences of failed obstetrical intubation may be disastrous. Failed intubation and resulting hypoxia is the leading anaesthetic cause of maternal mortality and morbidity. ${ }^{1}$ Failed intubation is estimated to occur in approximately 1 in 500 obstetric anaesthetics. ${ }^{2}$ The report on Confidential Enquiries into Maternal Deaths in the United Kingdom 1985-87 revealed that of the six deaths directly attributable to anaesthesia, four were due to problems associated with tracheal intubation. Of the two late deaths, one was again secondary to problems with tracheal intubation. ${ }^{1}$ Anecdotal reports concerning use of the laryngeal mask airway in obstetrical anaesthesia have been documented in the anaesthetic literature in recent years. ${ }^{3-8}$ The introduction of the LMA has added considerably to the anaesthetist's armoury. The purpose of this survey was to ascertain the role of the LMA in obstetrical anaesthetic practice in the United Kingdom and its possible use in a modified "failed intubation drill."

\section{Methods}

Questionnaires (Table I) were sent to 250 obstetrical units in the UK who each had $>1,000$ deliveries per annum.

\section{Results}

Two hundred and nine units responded to the questionnaire giving an overall response rate of $83.6 \%$. Two hundred and three $(97.1 \%)$ of these units used either Tunstall's or a modified Tunstall's failed intubation drill in the event of a failed obstetrical intubation, and six (2.9\%) units had no recommended protocol. One hundred and thirty (71.8\%) would only use the LMA to maintain oxygenation when tracheal intubation had failed and ven- 
TABLE I Questionnaire: The use of the laryngeal mask airway in obstetrical anaesthesia

1 Does your department lay down a procedure to be followed in a case of a difficult (unexpected/expected) intubation?* $\dagger$

2 Do you believe the LMA has a role in obstetrical anaesthesia?* $\dagger$

3 If your answer to the previous question was no, why do you consider that the LMA has no role in obstetrical anaesthesia?*†

4 Is an LMA available as an aid to providing anaesthesia within your obstetric department?*

5 Do you have a protocol for the use of the LMA in obstetrical anaethesia (emergency/elective)?*†

6 If you make use of the LMA within your obstetrical department, approximately how many times has it been required (emergency/ elective)?

7 Would you advocate a particular method of insertion of the LMA for obstetrical patients, and if so, what is your preferred technique?*†

8 Would you attempt to introduce a "bougie" or endotracheal tube (ETT) through the LMA in an obstetrical case?*†

9 If you use an LMA in obstetrical anaesthesia at what stage do you advocate its removal? $\uparrow$

10 Have you any personal anecdotal experience with the LMA in obstetrical anaesthesia? $\uparrow$

Obstetrical anaesthetists were asked to choose from the options, Yes or $\mathrm{No}^{*}$, and/or to provide brief detail $\uparrow$.

tilation using a face mask was inadequate. Fourteen (7.7\%) respondents said that the LMA should only be used in obstetrical anaesthesia by consultants. Four specified that they would only use the LMA for a spontaneously breathing patient. One obstetrical anaesthetist stated that he would consider using the LMA "electively" to secure the airway in obstetrical anaesthesia. Twentytwo obstetrical anaesthetists were against the use of the LMA for obstetrical anaesthesia. Their reasons are listed in Table II.

The LMA was available in 191 (91.4\%) units. Five units, where the LMA was not available, stated that they would consider using it in the event of a failed obstetrical intubation if it was available. Sixty-eight $(32.5 \%)$ units had an established protocol for the use of the LMA in a failed obstetrical intubation, and $16(7.7 \%)$ units were in the process of developing a protocol for its use. The majority of units had no experience in the use of the LMA in their obstetrical practice (Table III). Of the two units where the LMA had been used electively one specified that it was used to provide anaesthesia for removal of retained placenta requiring a general anaesthetic in the postpartum period. The unit that reported electively using the LMA twice did not specify the obstetrical procedures.

Fifty-seven (27.3\%) stipulated a particular method of insertion, most commonly that advocated by Brain (32), and eight the use of a laryngoscope to position the LMA.
TABLE II Reasons why the LMA has no role in obstetrical anaesthesia

\begin{tabular}{lcc}
\hline Reason & Number & $\%$ \\
\hline Risk of aspiration & 15 & 68.2 \\
Time wasted predisposing to hypoxia & 4 & 18.2 \\
Use not established in obstetrical practice & 2 & 9.1 \\
No reason given & 1 & 4.5 \\
\hline
\end{tabular}

TABLE III Number of times the LMA has been used in individual obstetrical units

\begin{tabular}{lcc}
\hline & Emergency No.(\%) & Elective No.(\%) \\
\hline None & $157(75.1)$ & $206(98.6)$ \\
Once & $32(15.3)$ & $2(0.9)$ \\
Twice & $13(6.2)$ & $1(0.5)$ \\
Three or more & $8(3.3)$ & \\
\hline
\end{tabular}

TABLE IV Removal of the LMA following its use in a failed obstetrical intubation

\begin{tabular}{lc}
\hline When to remove the LMA & Number (\%) \\
\hline Patient awake, position unspecified & $101(48.3)$ \\
Patient awake, lateral head down & $41(19.6)$ \\
Patient asleep, position unspecified & $2(0.95)$ \\
Patient asleep, lateral head down & $11(5.3)$ \\
No comment made & $55(26.2)$ \\
\hline
\end{tabular}

Two units recommended that cricoid pressure should be released prior to insertion of the LMA.

Sixty-four (30.6\%) obstetrical anaesthetists would consider introducing a gum elastic bougie or ETT through the LMA in a failed obstetrical intubation, and four would attempt to pass a fibreoptic scope through the LMA to try to facilitate intubation. Three respondents qualified their answers by adding that they would only attempt to pass a bougie or ETT through the LMA if there was a need for postoperative ventilation such as following confirmed aspiration of gastric contents or suxamethonium apnoea. Two others commented that once an airway had been established following failed intubation, to try to pass a bougie or ETT would be a "recipe for disaster."

The majority of anaesthetists would remove the LMA with the patient awake (position unspecified) or the patient awake and in the lateral head down position (Table IV).

Twenty-four anaesthetists had had personal experience with the LMA in obstetrical anaesthesia, eight of whom stated that the LMA had proved to be a "lifesaver." Two commented that their attempts to pass a bougie through 
the LMA and into the trachea had failed. Three had used the LMA, but were unable to maintain an airway with it and so subsequently removed it and used a face mask successfully.

\section{Discussion}

Failure to secure a patent airway is the leading cause of anaesthesia-related maternal death in the UK. Repeated attempts at tracheal intubation increase the incidence of hypoxia, aspiration and airway trauma. Hypoxia and death result not from failed intubation, but from failure to ventilate and from unrecognised oesophageal intubation. ${ }^{1,2,9}$ The priority is to keep the mother alive and to maintain the supply of oxygen to her lungs. It is important that a difficult or failed obstetrical intubation is managed according to a safe and logical protocol. The LMA was introduced by Brain in $1983^{10}$ and has been used successfully in patients of all ages in whom tracheal intubation has proved to be difficult. 11,12 However, the use of this device in obstetrical patients in whom intubation has failed remains controversial. In the UK, patients for emergency Caesarean section are usually anaesthetized by trainees, often out of hours. Trainees do not anaesthetize obstetrical patients in North America unsupervised. ${ }^{2}$ Also regional anaesthesia is more popular than general anaesthesia in North America for emergency Caesarean section, and therefore, failed intubation a less likely occurrence. Trainees in the UK will usually have completed at least 18 months of anaesthesia training before giving an anaesthetic for emergency Caesarean section unsupervised. It is, therefore, vital that when learning to administer obstetrical anaesthesia, all junior anaesthetists are taught a failed intubation drill, either Tunstall's ${ }^{13}$ or a modified Tunstall's. The purpose of following a drill in the event of a failed obstetrical intubation is to avoid aspiration of stomach contents and to keep the patient oxygenated until she resumes spontaneous ventilation, and allow her to regain consciousness. In most cases, the patient's lungs can be ventilated adequately with a face mask and in these patients insertion of the LMA would be meddlesome.

The majority, $71.8 \%$, of obstetrical anaesthetists in the UK would advocate the use of the LMA in a failed tracheal intubation in obstetric anaesthesia where ventilation using a face mask and oropharyngeal airway was impossible. However, $11.4 \%$ of anaesthetist's in this survey opposed the use of the LMA in obstetrical anaesthesia. The main reason given why the LMA should not be used is because of the risk of regurgitation of gastric contents (see Table II). Time wasted trying to insert the device may predispose to hypoxia, and its use not being established in obstetrical anaesthesia were the other reasons. The authors accept that these reasons are all valid, but would still advocate use of the LMA because in eight cases it proved to be a "lifesaver."

Freeman and Baxendale outlined some of the problems that may occur if the LMA is used by inexperienced anaesthetists. ${ }^{14}$ Firstly, under light anaesthesia, coughing, gagging, breath holding and laryngeal spasm may develop. Secondly, inability to place the LMA wastes more time and increases the likelihood of severe hypoxia. Thirdly, in order to tolerate the LMA, anaesthesia has to be sufficient to obtund laryngeal reflexes resulting in a greater possibility of aspiration. As the general use of the LMA for elective cases becomes more widespread, anaesthetists will be more confident in using the mask in emergency situations. The LMA does not protect the airway from regurgitation and aspiration of gastric contents may occur with its use in patients with full stomachs. ${ }^{15-17}$ Lower oesophageal sphincter barrier pressure may be reduced after insertion of an LMA during anaesthesia with spontaneous ventilation. ${ }^{18}$ Whether regurgitation occurs more frequently with the LMA or the face mask or with repeated attempts at intubation remains unclear. Gastric regurgitation was detected in $25 \%$ of patients during general anaesthesia administered via the LMA. ${ }^{19}$ However, Mikatti et al. could not demonstrate regurgitation in their study. ${ }^{20}$ Strang demonstrated that cricoid pressure in the presence of the LMA is effective in preventing reflux. ${ }^{21}$ Ansermino and Blogg found that successful insertion of the LMA occurred in only three of 20 patients who had cricoid pressure applied. The LMA was subsequently inserted successfully in all the patients after removal of cricoid pressure. ${ }^{22}$ These results are in direct conflict with those of previous studies ${ }^{23,24}$ that showed a failure rate of $3 \%$.

Many complications of failed tracheal intubation, including death, can be avoided by preoperative assessment. ${ }^{25}$ Availability of suggested equipment of a failed intubation, optimum intraoperative positioning of the parturient, correct application of cricoid pressure, and methods to confirm tracheal intubation are fundamental to safe practice. ${ }^{2}$

Our survey suggests that most obstetrical anaesthetists in the UK would, in the event of a failed intubation in an obstetrical patient for whom ventilation proves to be impossible, advocate insertion of the LMA before trying to establish a trans-tracheal airway, which carries its own inherent risks. Insertion of both the LMA and placement of a transtracheal airway may require prolonged release of cricoid pressure predisposing to regurgitation of gastric contents. ${ }^{26}$ In addition, in the event of a failed intubation, a relatively inexperienced anaesthetist's chance of placing a transtracheal airway correctly are slim, thus prolonging hypoxia. Other risks of placing a transtracheal airway include extravasation of gas into the extratracheal tissues 
and bleeding into the trachea and lungs. ${ }^{27}$ If difficulty occurs with the correct placement of the LMA, transient relaxation of cricoid pressure may be of benefit. Thorough familiarity with the LMA is essential, and persistent attempts to place it should be avoided if placement is unsuccessful. ${ }^{26}$ Once the LMA has been correctly placed and the patient safely anaesthetized, we recommend that no attempts are made to pass a gum elastic bougie or tracheal tube through the LMA into the trachea. The application of cricoid pressure may hinder the successful passage of a tracheal tube through the LMA. ${ }^{22}$ We believe that trying to pass a tracheal tube through the LMA may cause obstruction of an otherwise patent airway. We would also recommend that cricoid pressure should be maintained until the patient's laryngeal reflexes have returned and that the LMA be removed at the end of surgery with the patient awake and in the lateral head down position immediately after deflation of the cuff. The LMA is available in $91 \%$ of obstetrical units in the UK and we recommend that it should be added to the list of suggested equipment for management of a failed intubation.

\section{References}

1 Report on Confidential Enquiries into Maternal Deaths in England and Wales 1982-1984. London: Her Majesty's Stationery Office, May 1989: 73-87.

2 Davies JM, Weeks $S$, Crone LA, Pavlin E. Difficult intubation in the parturient. Can J Anaesth 1989; 36: 668-74.

3 Chadwick IS, Vohra A. Anaesthesia for emergency Caesarean section using the Brain laryngeal airway (Letter). Anaesthesia 1989; 44: 261-2.

4 McClune $S$, Regan M, Moore J. Laryngeal mask airway for Caesarean section. Anaesthesia 1990; 45: 227-8.

5 Priscu V, Priscu $L$, Soroker $D$. Laryngeal mask for failed intubation in emergency Caesarean section (Letter). Can J Anaesth 1992; 39: 893.

6 De Mello $W F$, Kocan $M$. The laryngeal mask in failed intubation (Letter). Anaesthesia 1990; 45: 689.

7 Storey $J$. The laryngeal mask for failed intubation at caesarean section (Letter). Anaesth Intensive Care 1992; 20: 118-9.

8 Wiliams $A R$, Cone $A$. The laryngeal mask airway - suboptimal availability, a cause for concern (Letter). Anaesthesia 1992; 47: 1005.

9 Tunstall ME. Failed intubation in the parturient (Editorial). Can J Anaesth 1989; 36: 611-3.

10 Brain AIJ. The laryngeal mask: a new concept in airway management. Br J Anaesth 1983; 55: 801-5.

11 Allen JG, Flower EA. The Brain laryngeal mask. An alternative to difficult intubation. Br Dental J 1990; 168: 202-4.

12 Denny NM, DeSilva KD, Webber PA. Laryngeal mask airway for emergency tracheostomy in a neonate (Letter). Anaesthesia 1990; 45: 895.

13 Tunstall ME. Failed intubation drill. Anaesthesia 1976; 31: 850.

14 Freeman $R$, Baxendale $B$. Laryngeal mask airway for Caesarean section (Letter). Anaesthesia 1990; 45: 1094-5.

15 Nanji GM, Maltby JR. Vomiting and aspiration pneumonitis with the laryngeal mask airway. Can J Anaesth 1992; 39: $69-70$.

16 Griffin RM, Hatcher IS. Aspiration pneumonia and the laryngeal mask airway. Anaesthesia 1991; 45: 1039-40.

17 Koehli $N$. Aspiration pneumonia and the laryngeal mask airway (Letter). Anaesthesia 1991; 46: 419.

18 Rabey PG, Murphy PJ, Langton JA, Barker P, Rowbotham $D J$. Effect of the laryngeal mask airway on lower oesophageal sphincter pressure in patients during general anaesthesia. Br J Anaesth 1992; 69: 346-8.

19 Barker P, Langton JA, Murphy P, Rowbotham DJ. Regurgitation of gastric contents during general anaesthesia using the laryngeal mask airway. Br J Anaesth 1992; 69: 314-5.

20 El Mikatti N, Luthra AD, Healy TEJ, Mortimer AJ. Gastric regurgitation during general anaesthesia in the supine position with the laryngeal and face mask airways. $\mathrm{Br}$ J Anaesth 1992; 69: 529P-530P.

21 Strang TI. Does the laryngeal mask airway compromise cricoid pressure? Anaesthesia 1992; 47: 829-31.

22 Ansermino JM, Blogg CE. Cricoid pressure may prevent insetion of the laryngeal mask airway. Br J Anaesth 1992; 69: 465-7.

23 Heath $M L$, Allagain J. Intubation through the laryngeal mask. A technique for unexpected difficult intubation. Anaesthesia 1991; 46: 545-8.

24 Brimacombe J. Cricoid pressure and the laryngeal mask airway (Letter). Anaesthesia 1991; 46: 986-7.

25 McIntyre JWR. The difficult tracheal intubation. Can J Anaesth J 1987; 34: 204-13.

26 Pennant JH, White PF. The laryngeal mask airway. Its uses in anesthesiology. Anesthesiology 1993; 79: 144-163.

27 King TA, Adams AP. Failed tracheal intubation. $\mathrm{Br} \mathrm{J}$ Anaesth 1990; 65: 400-14. 